\title{
Observations on patients dysphasic after stroke
}

\author{
VALERIE EATON GRIFFITH
}

These observations have built up during 14 years' involvement with patients dysphasic after stroke. ${ }^{1}$ This includes both personal contact over a long period and the opportunity to observe many of the thousand patients in the Chest, Heart, and Stroke Association Volunteer Stroke Scheme. ${ }^{2}$

\section{Use of speech}

Speech appears to be dependent on more than simply "finding the words"; personality, temperament, intelligence, experience, and creating favourable conditions all play a part. In normal circumstances everyone uses speech differently and, perhaps what is more important, each person to some extent changes his way of speaking according to circumstances. If this happens normally how much more is it to be expected when speech is affected by stroke and there is exaggeration of the "stop-go" process. A dysphasic patient's speech is plainly linked to the way he spoke before the stroke, so whatever helped to trigger off his speech then will have remained the same. It is the discovery of these "triggers" that produces the most rewarding response in the patient. Several points arise from this.

Speech comes more easily when there is an urgent thought to express. Language seems to be released by the irresistible need to impart a prized piece of information; at these times the words are not consciously sought. All of us periodically lose a word and are told "forget it, think of something else-it will come" and it does. This has removed the burden of word finding and allowed unbidden thought to produce the word. It appears to apply particularly in dysphasia. Improved speech because of an urgent need for expression was illustrated when, after an outing, some patients had to cross a road braving the London rush-hour traffic to their bus and arrived home nearly two hours late. Far from grumbles or distress this caused excitement and involvement, and the patients spoke as if a dam had burst.

A patient after stroke will use all his available speech if what he is trying to talk about is of interest to him. Conversely if the patient has no interest in a subject he may resist the use of what speech he has.

Relevance is important. Some patients were taken to see a reconstructed mill working as it had 100 years ago. Two of the patients once worked at a similar mill and were discovered talking to the curator with a flow of language unknown since their stroke, even to the extent of using the old trade words that only they and the curator understood.

Stimulation is vital. Unless something can be found to dispel the boredom and inertia in which the patient lives, little can be achieved. One can build on what a patient after stroke actively dislikes as well as on likes, hobbies, and interests.

The effect of one notion triggering off the next is often lost. Constant help with suggesting things to do, with a general plan and timetable, can help considerably.

\section{Alternative ways of communicating}

Where the ability to mime has been affected along with speech, repeated gestures, at first thought meaningless, may represent something specific and thus become a communication point.

Great Missenden, Buckinghamshire

VALERIE EATON GRIFFITH, originator of Volunteer Stroke Scheme
One patient who was totally aphasic was able to "mirrorwrite" in the air to his wife. Another, an ex-sailor with severe dysphasia, could remember the Morse code and could read or write this more easily than he could words.

Many patients with a stroke seem to speak at their best on the telephone. It has even been found that two "mock" telephones used by the patient and the person to whom he is talking may produce better speech.

When a patient's first language is not English but English has been used at the time of stroke and indeed for many years past after the stroke speech in English is equal or slightly better than that in the language of birth.

\section{Effect of morale on the use of speech}

Depression must surely be a natural result of the effects of stroke. Patients with a stroke must be allowed to show distress and to feel depressed; to deny them this (unless it is excessive) is to deny them the chance to be normal human beings. To this end, too, the phrase "personality change" should be avoided whenever possible. These are devastating words for the families, who as a result can change their attitude towards their loved one, believing him to have become a stranger. Somebody who has had a bad stroke will never before have met such a personal disaster to the ego. Thus the visible change may well be a natural reaction to the disaster rather than a real change of personality.

Confidence can become so low that it amounts to a loss of ego. Unless it is raised a catastrophic apathy can result, which will limit progress. Any achievement helps to avoid the downward spiral of low confidence, no achievement, less confidence, apathy. Undoubtedly the world in which they are living seems to be perpetually lowering them in their own self-esteem, so it is important that much attention is paid to their personal dignity. This sense of shame can apply also to families, whose feelings seldom go unnoticed by the patient. They may also fear that their less attractive appearance will affect relations with family and friends.

High intelligence and previous heavy responsibilities may actively hold back recovery. The goals look impossibly far away and the fall from the position held is so extreme that there is no place (work, home, or community) where degradation is not acutely felt.

Stress is inevitable in a household where someone has had a stroke. Some, caused by small irritants, can be reduced, but to leave the patient out in the cold is likely to increase frustration. Sharing news, even when bad, helps avoid exclusion and is the lesser of two evils. To deny him the right to share trouble is to increase stress and also to drain from him the weapon of his own courage.

An inevitable worry in these families is that for one member there is too much to do and the other too little. This produces a sense of guilt on both sides, the patient because he cannot help and the spouse because there is too little time and energy to give to the patient. Relief for the one who is toiling will also help the patient, and a periodic holiday separation can benefit both.

Families do not always appreciate the extent of loss of comprehension in the patient, who often tries to defend himself by pretending to understand, which leads to further stress. The scorn of some small children towards a parent or grandparent who can no longer talk or handle money can be very distressing. Both these aspects may be alleviated by helping the family to understand what has happened. Often patients and their families 
experience a bitter period some six to nine months after the stroke when the initial rank-closing and response to calamity is over, energy is running low, and a full realisation of the possible future hits them. At this time help and encouragement from outside have a great effect. The family's wellbeing is fundamental to a patient's progress and clearly support is essential.

\section{Motivation}

Much is talked about the motivation of patients in their efforts to speak again after a stroke and to use fully what remains to them, but motivation has two parts. The first is the need to recognise that something exists for which it is worth getting better. This is not always obvious to others. For instance, a patient may have a splendid family, friends, and hobbies, yet over-protection can make him feel there is no future for him.

The second part of motivation is willpower. A normally strong will can become quenched, producing an uncharacteristic lack of drive and initiative. Not until someone else had produced the spur did one woman rouse herself, and then begin to relish the work she would normally have driven herself to undertake. This was a daily repeated pattern for two and a half years until slowly her latent will-power began to reappear. Loss of normal initiative is also shown. One patient would leave the unopened jigsaw where it was left by his side. Not until it was put on the table right in front of him did he do it, and then with obvious pleasure.

Motivation will also be reduced when there is isolation from ordinary life. The need to share normal experiences and to take some risks is urgent. A patient needs to give, at times to take over with zest the role of comforter, a rare role indeed for a patient after a stroke.

\section{Rehabilitation}

Rehabilitation to ensure that each patient is as independent as possible is vitally important. But physical rehabilitation is tiring, and a tired patient is in no condition to fight for the return of intellectual functions. The struggle for expression and the use of intellect must take priority since it is the return of these-so far as possible-that will make life worth living.

Orthodox rehabilitation of patients who have had a stroke tends to concentrate exclusively on the problems of hemiplegia and speech. The need for general mental stimulation and the practice of intellectual skills (such as memory and concentration) does not appear to be recognised. Yet without time spent on these aspects rehabilitation is incomplete, and whatever skills have been acquired may very well not be used.

After the rehabilitation period, spending a high percentage of a patient's life and energy visiting hospitals for treatment must surely be recommended only if there is a very real expectation of further recovery, because the costs may be dear. These include a growing dependence on institutions, difficulty in accepting lingering handicaps, and, most of all, being too weary to join in daily life.

\section{Some general points}

The performance of some patients improves after poststroke fits. Complicated physical aids may be immensely difficult for a dysphasic stroke patient to manage. Often they seem to do better with small aids thought up by themselves and their helpers. A patient's performance is inevitably affected by the normal ups and downs. It has been noticed, however, how much intellectual function and the will to fight improve when tranquillisers are withdrawn. Occasionally a dyslexic child has understood a dysphasic's writing when this has not been intelligible to anyone else.
Any inventiveness a patient might once have had is enormously lessened after a bad stroke. In a game sometimes played at clubs each person has to mime an action while everyone else tries to guess what it is. Patients are quite unable to think of anything to mime, though they are enthusiastic guessers. This inability is not restricted to those who normally find mime difficult.

One patient (a right-handed man with a dominant-side stroke) had a strange inability to estimate time passing. His speech returned to near normal but he had a short memory span and much trouble with numbers, money, and reading. His wife once dropped him off to pick blackberries while she shopped. After about ten minutes, although he had a watch, could tell the time, and had picked only a few blackberries, so strong was his feeling that a long time had passed that he ignored these factors, panicked, strode off at random, and was eventually found after a long search.

Some patients seem unusually sensitive to noise. This does not appear to be simply a question of concentration or age, but as one patient put it, "it echoes inside." Someone with reasonable comprehension can be helped when trying to read if he hears a simultaneous tape recording of the same words spoken fairly slowly. The pattern of dreams sometimes seems to change. For instance, of eight patients at one club six said they had never dreamt since their stroke although they had done so before; one had more dreams but these were now in black and white, and the eighth had not changed. Sometimes when there seems to be difficulty in distinguishing related colours, a black and white picture on television has appeared clearer and more easily understood than a coloured one. The re-establishment of humour is one of the best antidotes to loss of confidence, and happiness in itself has a vital place in rehabilitation.

Finally, hope for the future is essential but over-optimism can deter patients from using to the best advantage what is left. It is good to emphasise that the fight for recovery itself is worth the effort. Taken at its lowest value this will promote some inner peace and self-respect.

Requests for reprints: Chest, Heart, and Stroke Association, Tavistock House North, Tavistock Square, London WC1H 9JE.

\section{References}

${ }^{1}$ Eaton Griffith V. A stroke in the family. London: Wildwood, 1975.

2 Eaton Griffith V, Miller CL. Volunteer stroke scheme for dysphasic patients with stroke. $\mathrm{Br}$ Med $\mathcal{F} 1980 ; 281: 1605-7$.

(Accepted 8 October 1980)

Is any surgical treatment feasible in an 80-year-old with arthritis of the spine, degenerative disc narrowing, and neurological signs in his legs?

Surgical treatment is not only feasible but may be essential if the patient is to continue to walk. Hypertrophic osteoarthrosis combined with degenerative disc narrowing may lead to degenerative spondylolisthesis or prolapse of disc material into the spinal canal. The narrowing of the spinal canal thus caused may give rise to spinal stenosis. The patient will complain of increasing difficulty in walking with weakness in the legs, paraesthesiae in the feet, and pains down the front or back of the legs. Back pain, although often present, is not usually severe. Occasionally there is disturbance of micturition with hesitancy and retention. The most characteristic finding is that the symptoms are relieved by sitting with the spine flexed or by leaning forward over a stick or frame. Myelography may show a complete block, usually at the $L$ 4/5 level, although this is not always shown unless the procedure is done with the spine in extension. Surgical treatment is carried out to decompress the narrowed spinal canal. Laminectomy and facetectomy at several levels may be required. Stabilisation is not necessary in this older age group. 